\title{
Equatorial Oceanic Waves and the Evolution of 2007 Positive Indian Ocean Dipole
}

\author{
Iskhaq Iskandar ${ }^{1,4,5, *}$, Wijaya Mardiansyah ${ }^{1}$, Dedi Setiabudidaya ${ }^{1}$, Pradanto Poerwono $^{1}$, \\ Netty Kurniawati ${ }^{1}$, Fadli Saymsuddin ${ }^{2}$, and Motoki Nagura ${ }^{3}$ \\ ${ }^{1}$ Jurusan Fisika, Fakultas Matematika dan Ilmu Pengetahuan Alam, Universitas Sriwijaya, Inderalaya, \\ Sumatra Selatan, Indonesia \\ ${ }^{2}$ Agency for Assessment and Application Technology, Jakarta, Indonesia \\ ${ }^{3}$ Research Institute for Global Changes, JAMSTEC, Yokosuka, Japan \\ ${ }^{4}$ Pusat Study Geo-hazard dan Perubahan Iklim, Fakultas Matematika dan Ilmu Pengetahuan Alam, Universitas Sriwijaya, \\ Inderalaya, Sumatra Selatan, Indonesia \\ ${ }^{5}$ Pusat Penelitian Lingkungan Hidup, Universitas Sriwijaya, Inderalaya, Sumatra Selatan, Indonesia
}

Received 26 March 2014, revised 12 August 2014, accepted 25 August 2014

\begin{abstract}
The role of equatorial oceanic waves on the evolution of the 2007 positive Indian Ocean Dipole (pIOD) event was evaluated using available observations and output from a quasi-analytical linear wave model. It was found that the 2007 pIOD event was a weak and short-lived event: developed in the mid-summer (July), matured in the early-fall (September), and terminated in the mid-fall (October). The evolution of the 2007 pIOD event was linked to the equatorial wave dynamics. The event development was associated with the generation of upwelling equatorial Kelvin waves (westward current anomalies) generated by easterly wind anomalies. The event termination was associated with the occurrence of eastward zonal current anomalies resulting from a complex interplay between the wind-forced down welling Kelvin waves and the eastern-boundary-reflected Rossby waves. Results from a quasi-analytical linear wave model show that during the event development and maturation, the wind-forced Kelvin waves played a dominant role in generating zonal current anomalies along the equatorial Indian Ocean, while the easternboundary-reflected Rossby waves tended to weaken the wind-forced Kelvin wave signals. During the event termination our model shows that the initiation of anomalous eastward current resulted from the reflected Rossby waves at the eastern boundary. The wind-forced Kelvin waves associated with the seasonal reversal of the monsoon further strengthened the eastward zonal currents generated by the boundary-generated Rossby waves in late-October/early-November. This highlights the importance of the eastern-boundary-reflected Rossby waves on the IOD event termination.
\end{abstract}

Key words: Indian Ocean Dipole, Kelvin waves, RAMA buoys, Rossby waves

Citation: Iskandar, I., W. Mardiansyah, D. Setiabudidaya, P. Poerwono, N. Kurniawati, F. Saymsuddin, and M. Nagura, 2014: Equatorial oceanic waves and the evolution of 2007 positive Indian Ocean Dipole. Terr. Atmos. Ocean. Sci., 25, 847-856, doi: 10.3319/TAO.2014.08.25.01(Oc)

\section{INTRODUCTION}

Indian Ocean Dipole (IOD), a coupled ocean-atmosphere mode at inter-annual time scale, is associated with an oscillation of sea surface temperature (SST) in the tropical Indian Ocean. A typical positive IOD (pIOD) event is characterized by a warm (cold) SST anomaly in the western (southeastern) tropical Indian Ocean, while a negative IOD (nIOD) event has opposite features (Saji et al. 1999; Webster et al. 1999; Murtugudde et al. 2000). A swing in the SST and

\footnotetext{
* Corresponding author

E-mail: iskhaq@mipa.unsri.ac.id
}

zonal wind anomalies associated with the IOD event has a typical biennial variation: the SST and zonal wind anomalies change signs from one year to the following year (Saji et al. 1999, McPhaden and Nagura 2014). Observational records, however, have shown a consecutive pIOD event, in which a positive event is followed by another positive event (Meyers et al. 2007; Cai et al. 2009). In particular, the 2007 event was identified as a pIOD-La Niña pair (Behera et al. 2008).

The rare co-occurrence of the $\mathrm{PIOD}$ and La Niña pair in 2007 calls for a dynamic assessment on the role of oceanic equatorial waves on the evolution of the 2007 pIOD event. 
Behera et al. (2008) suggested that easterly wind anomalies associated with subsidence over the Maritime continent generated upwelling Kelvin waves along the equatorial Indian Ocean. These waves caused shoaling of the thermocline in the eastern Indian Ocean leading to the evolution of the pIOD event. Cai et al. (2009) showed that the upwelling Rossby waves radiating from the eastern boundary play an important role in generating the SST gradient.

We quantitatively examine the role of equatorial waves on the evolution of the IOD event in this study using a combination of observational data and outputs from a wind-driven, linear, continuously stratified long wave ocean model. This model provides an opportunity to quantitatively identify the source of energy for these waves during the IOD event evolution. We focus on the evolution of a unique 2007 pIOD and La Niña event pair in which direct observations completely covered the event evolution. Results from this study complement that of Cai et al. (2009), who used Argo observations to study the evolution of this event.

The paper is organized as follows. Section 2 describes the datasets and the liner model used in the present study. The observed evolution of the 2007 pIOD is presented in section 3. Section 4 discusses the role of directly-forced and boundary-reflected equatorial waves in the evolution of IOD events using a linear wave model. Conclusions are presented in section 5 .

\section{DATA AND MODEL DESCRIPTIONS}

\subsection{Data}

The QSCAT daily winds, which are available from 19 July 1999 to 29 October 2009, were used in this study. The data has horizontal resolution of $0.25^{\circ} \times 0.25^{\circ}$. The SST data from January 1998 to December 2009 were derived from the Tropical Rain Measurement Mission (TRMM) data. This data has temporal and horizontal resolution of 7 days and $0.25^{\circ}$, respectively.

In addition, near-surface velocity data from the Ocean Surface Current Analysis-Real time (OSCAR) project were used (Bonjean and Lagerloef 2002). The data were available from 21 October 1992 to 1 September 2010 with horizontal resolution of $1^{\circ} \times 1^{\circ}$ and temporal resolution of 5 days. Daily temperature time series from the Research Moored Array for African-Asian-Australian Monsoon Analysis and Prediction (RAMA) buoy (McPhaden et al. 2009) in the central $\left(0^{\circ}\right.$, $\left.80.5^{\circ} \mathrm{E}\right)$ and eastern $\left(1.5^{\circ} \mathrm{S}, 90^{\circ} \mathrm{E}\right)$ equatorial Indian Ocean were also used in this study. ADCP moorings as part of the RAMA program were deployed in the central $\left(0^{\circ}, 80.5^{\circ} \mathrm{E}\right)$ and eastern $\left(0^{\circ}, 90^{\circ} \mathrm{E}\right)$ equatorial Indian Ocean. At $80.5^{\circ} \mathrm{E}$ the mooring provides daily subsurface current data down to $175 \mathrm{~m}$ depth for the period from 27 October 2004 to 17 October 2008 . The $90^{\circ} \mathrm{E}$ mooring provides subsurface current data up to $300 \mathrm{~m}$ depth from 14 November 2000 to 19 March 2009. We also used a 10-m depth ocean current meter in- stalled on the RAMA buoy at $\left(0^{\circ}, 90^{\circ} \mathrm{E}\right)$. This current meter provides near-surface current data from 12 September 2006 to 21 November 2009

The vertical potential density profiles were calculated using temperature and salinity data from Argo float observations provided by the Institut français de recherche pour l'exploitation de la mer (IFREMER) Coriolis data center (Roemmich and Gilson 2009). The data were available from near surface up to $2000 \mathrm{~m}$ with vertical resolution from 5 - $20 \mathrm{~m}$ for the upper $320 \mathrm{~m}$. The data were mapped with a temporal resolution of 7 days on $0.5^{\circ} \times 0.5^{\circ}$ horizontal.

Mean climatologies of all variables were calculated from time series over the period January 2002 to December 2008, except for the near-surface currents, which were calculated as a deviation from a long-term mean of January 2007 to December 2008. The anomaly fields for all variables were then constructed based on deviations from their mean climatology. The anomalous data were finally smoothed with a 15-day running mean filter.

\subsection{Model Descriptions}

The model used in this study is a wind-driven, linear, continuously stratified long-wave ocean model (Nagura and McPhaden 2010a, b). The model used the first 10 baroclinic modes and 15 meridional modes (the Kelvin mode and the first 14 Rossby modes). Mean density stratification from the observed Argo temperature and salinity from the surface to $4000 \mathrm{~m}$ was used to calculate the vertical modes. Since the Argo profiles only provide data up to $2000 \mathrm{~m}$ depth, we simply extrapolated the profile of potential density up to $4000 \mathrm{~m}$ depth. Note that the density stratification was averaged over the region $15^{\circ} \mathrm{S}-15^{\circ} \mathrm{N}$ and $40^{\circ}-100^{\circ} \mathrm{E}$. The phase speeds for the first and second baroclinic mode Kelvin waves were 2.5 and $1.55 \mathrm{~m} \mathrm{~s}^{-1}$, respectively. These results are in agreement with previous studies in the equatorial Indian Ocean (Clarke and Liu 1993; Han 2005).

The model is unbounded in the meridional direction and the zonal domain spans $40^{\circ}-100^{\circ} \mathrm{E}$, with straight northsouth meridional walls at the eastern and western boundaries. Following observational results (le Blanc and Boulanger 2001), we used $85 \%$ as reflection efficiency at both the eastern and western boundary. The grid sizes are $\Delta x=2^{\circ}$ and $\Delta t=12 \mathrm{hrs}$. The damping coefficient is $A / c_{n}^{2}$, where the subscript $n$ denotes the vertical mode number. The parameter $A$ is an arbitrary constant chosen so that the damping coefficient for the first vertical baroclinic mode is (12 months $)^{-1}$. The model is forced for the period 1 January 1980 to 30 April 2010 with daily wind stresses from the European Centre for Medium Range Forecasting (ECMWF) reanalysis.

\section{EVOLUTION OF 2007 INDIAN OCEAN DIPOLE}

\subsection{Surface Evolution}


The 2007 pIOD evolution is indicated by the Dipole Mode Index (DMI) as shown in Fig. 1a. The DMI tended to increase by July, co-occurred with the Niño 3.4 index evolution (Fig. 1b). This unusual pIOD-La Niña pair has been reported by Behera et al. (2008). After a short weakening in late-July/early-August, the DMI persisted, increasing from mid-August and reached its peak in September. The increase in DMI co-occurred together with the Niño 3.4 index. While the Niño3.4 index continued to grow, the DMI started to decrease in late-September. The DMI changed sign by the end of October as the pIOD event was completely terminated. However, La Niña was then already fully established and persisted until February.

The spatio-temporal evolution of the 2007 pIOD event is described in Fig. 2. Apparently, easterly wind anomalies in the equatorial Indian Ocean were observed during May 2007 (Fig. 2a). These easterlies were associated with a negative SST anomaly in the southeastern equatorial Indian Ocean and positive SST anomaly over most of the western tropical Indian Ocean. Behera et al. (2008) pointed out that these easterly wind anomalies in Spring 2007 were a key feature for the evolution of the 2007 pIOD event. These easterlies, however, were weakened in June (not shown). In July easterly winds and southeasterly winds were observed along the equator and along the southern coast of Sumatra and Java, respectively (Fig. 2b). A typical pIOD pattern was established in September (Fig. 2c). A maximum negative SST anomaly located to the west of Sumatra was observed and had values exceeding $-1.2^{\circ} \mathrm{C}$. A positive SST anomaly of the order of about $0.8^{\circ} \mathrm{C}$ occupied the western-central Indian Ocean. Associated with the SST pattern, easterly wind anomalies were observed along the equator from the central basin to the coast of Sumatra, while anomalous southeaster- ly winds were observed along the coast of Sumatra reflecting strong upwelling in that region (Fig. 2c).

The Indian Ocean returned to normal conditions in boreal fall of October - November as the SST dipole-pattern demised (Fig. 2d). A warm SST anomaly occupied most of the eastern equatorial region, while a cold SST anomaly was loaded in the western equatorial region. In addition, the easterly wind anomalies along the equator also changed into westerly wind anomalies.

\subsection{Subsurface Evolution}

The corresponding temporal evolution of zonal currents observed in the central and eastern equatorial Indian Ocean during January - December 2007 are presented in Fig. 3. The eastward flowing Wyrtki jet that occurs during monsoon transition periods in April/May was observed in the central equatorial Indian Ocean during April 2007 (Figs. 3a - b). This eastward jet can be observed from near surface (Fig. 3a) down to $100 \mathrm{~m}$ depth (Fig. 3b). Near-surface zonal current in the central equatorial Indian Ocean rapidly strengthened toward the west in early-August and reached its maximum of about $60 \mathrm{~cm} \mathrm{~s}^{-1}$ in late-August (Fig. 3a). It gradually decreased in September before it turned toward the east in early-October. In the deeper layer, however, it showed eastward current anomalies from mid-July to mid-August (Fig. 3b). Strong westward current anomalies were observed in September with a maximum peak of about $65 \mathrm{~cm} \mathrm{~s}^{-1}$. A fall Wyrtki jet was observed from the surface down to about 100 $m$ depth in October - November 2007 (Figs. 3a - b) as the pIOD was completely terminated.

In the eastern equatorial Indian Ocean, however, the spring Wyrtki jet was only observed near the surface
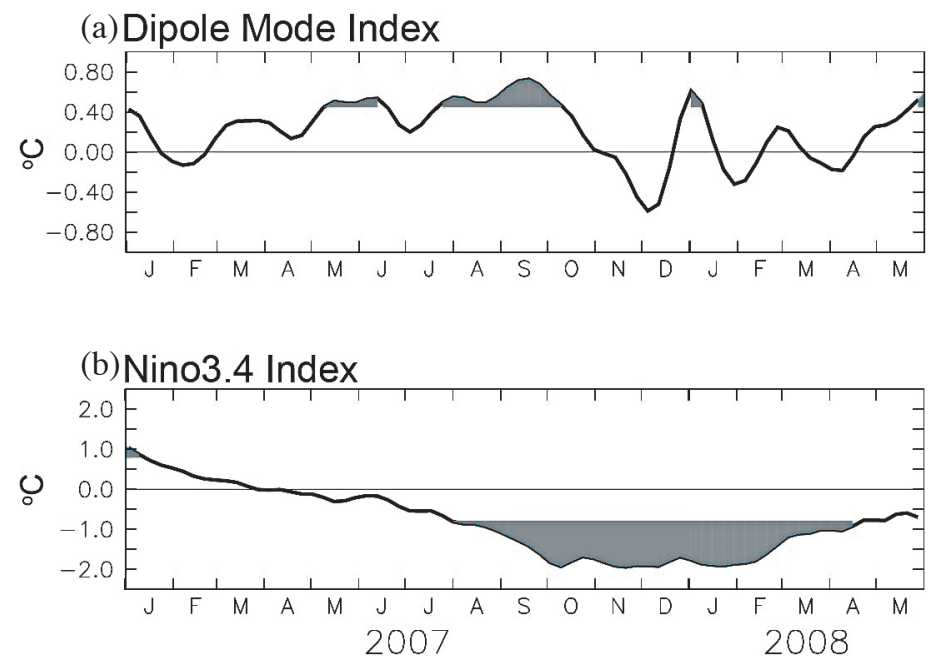

Fig. 1. Time series of (a) Dipole Mode Index (DMI), and (b) Niño 3.4 Index during January 2007 through May 2008. The DMI is defined as the difference in SST anomaly between western region $\left(50^{\circ}-70^{\circ} \mathrm{E}, 10^{\circ} \mathrm{S}-10^{\circ} \mathrm{N}\right)$ and eastern region $\left(90^{\circ}-110^{\circ} \mathrm{E}, 10^{\circ} \mathrm{S}-\right.$ Equator $)$. The Niño 3.4 Index is defined as an averaged SST anomaly in the region bounded by $5^{\circ} \mathrm{N}-5^{\circ} \mathrm{S}$, from $170^{\circ}-120^{\circ} \mathrm{W}$. Values larger (smaller) than one standard deviation are highlighted in gray. 
(a) May 2007

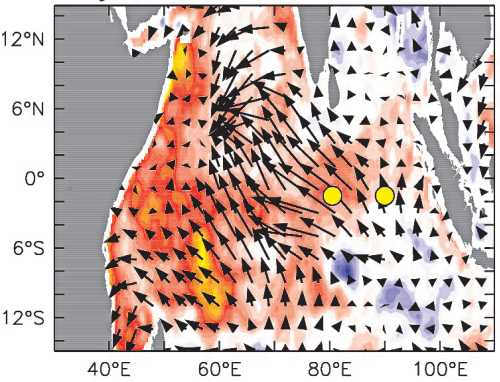

(c) September 2007

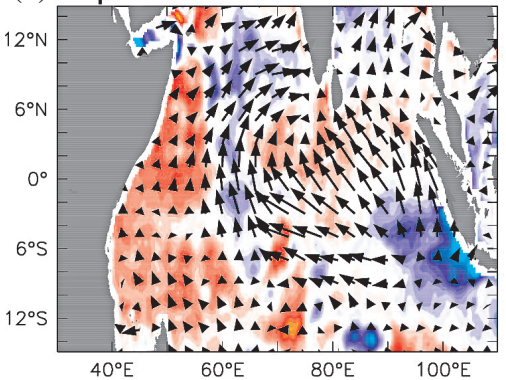

(b) July 2007

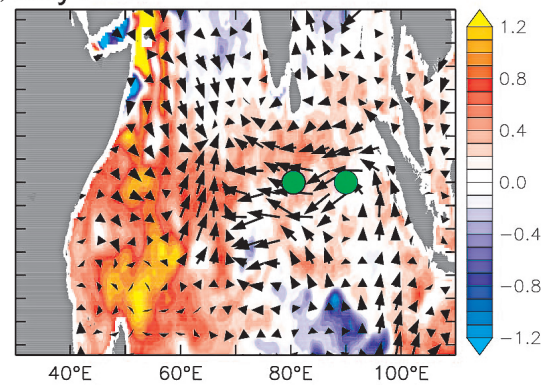

(d) November 2007

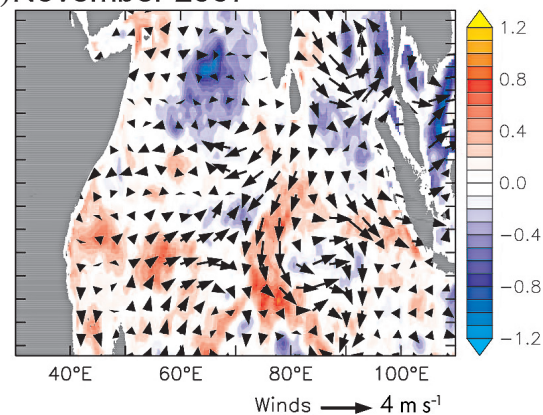

Fig. 2. SST (shaded) and surface wind (vectors) anomalies averaged during (a) May, (b) July, (c) September, and (d) November 2007. The anomalies are obtained by subtracting the mean climatologies, then smoothing with a 15-day running mean filter. The location of RAMA buoys is shown in panel (a) and that the ADCP moorings are presented in panel (b).

(a) OSCAR zonal current at $0^{\circ}, 80.5^{\circ} \mathrm{E}$

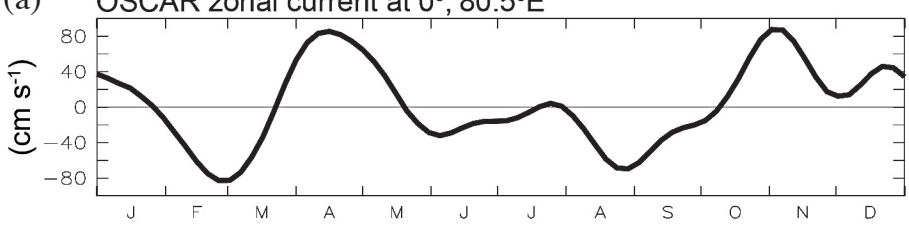

(b) ADCP zonal current at $0^{\circ}, 80.5^{\circ} \mathrm{E}$

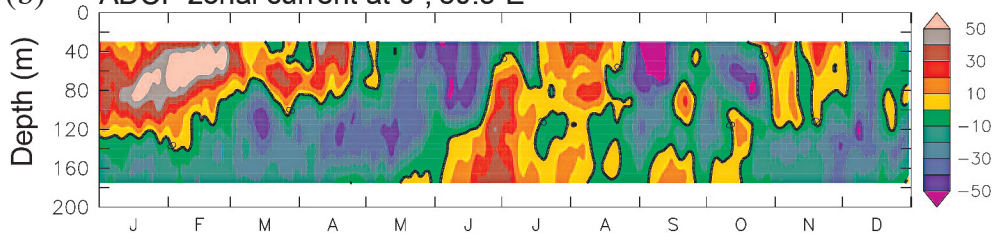

(c) OSCAR zonal current at $0^{\circ}, 90^{\circ} \mathrm{E}$
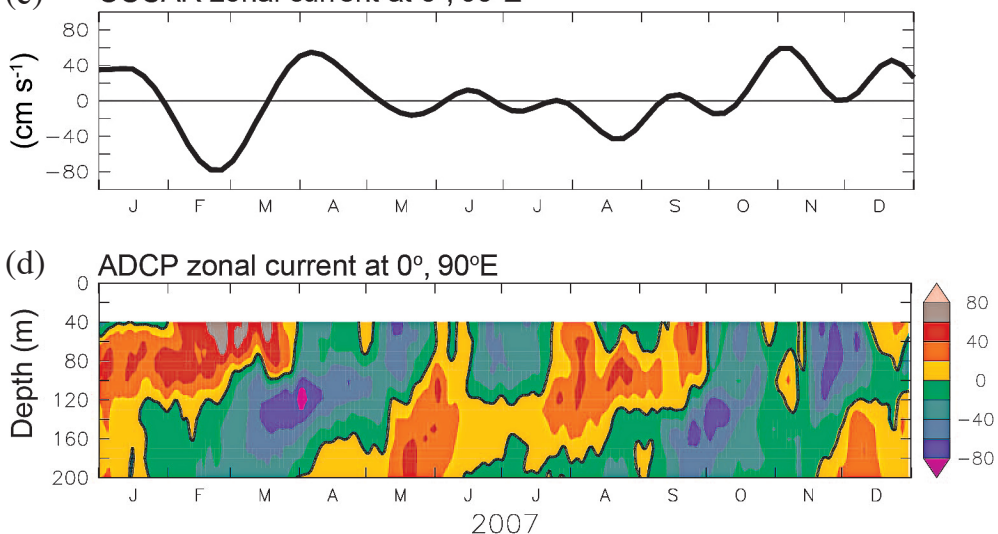

Fig. 3. Time series of zonal current anomalies from OSCAR and the time-depth sections of zonal current anomalies from ADCP mooring at (a,b) $0^{\circ}$, $80.5^{\circ} \mathrm{E}$, and $(\mathrm{c}, \mathrm{d}) 0^{\circ}, 90^{\circ} \mathrm{E}$. The anomalies are obtained by subtracting the mean climatologies, then smoothing with a 15 -day running mean filter. 
(Fig. 3c). The subsurface zonal current anomalies at the deeper level showed an opposite direction (Fig. 3d). The zonal current anomalies indicated westward anomalies from May and stayed westward until July, except for short-term variability forced by intra-seasonal winds in June (Figs. 3c - d). After a short-reversal to the eastward current anomalies in the late-July/early-August, the zonal currents again switched to the westward until mid-September. Interestingly, although the zonal current anomalies in the central equatorial Indian Ocean are strongly westward (Figs. 3a - b), we observed eastward zonal currents in the eastern equatorial Indian Ocean in September (Figs. 3c - d). These eastward zonal currents may play an important role in the termination of the 2007 pIOD event and it will be discussed in section 4. A fall Wyrtki jet was also observed in the eastern equatorial Indian Ocean in October/November (Fig. 3a), though with a smaller amplitude observed in the deeper levels (Fig. 3d).

Corresponding subsurface signals for the evolution of the pIOD event can be observed in the subsurface temperature profile (Horii et al. 2008). Large negative temperature anomalies $\left(<-4^{\circ} \mathrm{C}\right)$ were observed in the upper thermocline at all mooring locations prior to the 2007 pIOD event (Figs. $4 \mathrm{a}-\mathrm{b}$ ). In the central equatorial Indian Ocean, these negative anomalies continued for several months until June 2007 though with smaller amplitude (Fig. 4a). There was a short weakening of the negative temperature anomalies in July associated with strong eastward current anomalies during that period (Figs. 3a-b). The negative anomaly de- veloped again in late-July as the pIOD started to develop, and it lasted until late-September/early-October (Fig. 4a). We note that the strongest negative temperature anomaly of $<-3^{\circ} \mathrm{C}$ occurred in late-September/early-October, when the surface IOD signal disappeared. Negative subsurface temperature anomalies that occurred in mid-October terminated as the temperature changed to positive anomalies from the surface down to $300 \mathrm{~m}$ depth. This change was associated with the generation of the fall Wyrtki jet in October/November (Figs. 3a-b).

The initiation of negative temperature anomalies in the eastern equatorial Indian Ocean was observed in May 2007, two months before the onset of the 2007 pIOD event (Fig. 4b). The negative anomaly lasted for about 6 months until mid-October before it suddenly changed into a positive anomaly at all water columns from the surface down to $300 \mathrm{~m}$ depth during late-October/early-November. We note that a maximum negative anomaly of about $-4^{\circ} \mathrm{C}$ occurred in September - October, during which subsurface isotherm spreading occurred.

\section{ROLE OF EQUATORIAL WAVES}

The evolution of the IOD event is strongly influenced by the equatorial oceanic wave dynamics (Chamber et al. 1999; Webster et al. 1999; Vinayachandran et al. 1999; Rao et al. 2002; Feng and Meyers 2003; Rao and Yamagata 2004; Yuan and Liu 2009; Iskandar et al. 2013). Thermocline
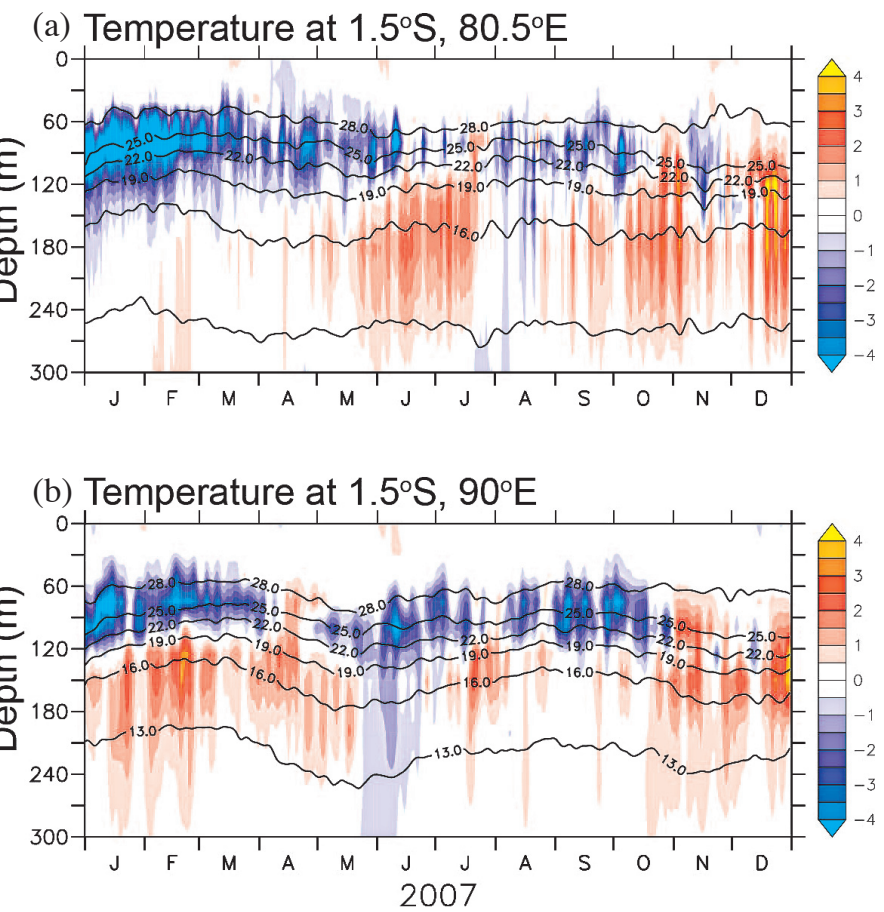

Fig. 4. Time-depth sections of the subsurface temperature from RAMA buoys at (a) $1.5 \mathrm{~S}^{\circ}, 80.5^{\circ} \mathrm{E}$, and (b) $1.5 \mathrm{~S}^{\circ}, 90^{\circ} \mathrm{E}$. Colors (contours) indicate anomalies (climatologies), with a contour interval of $2^{\circ} \mathrm{C}$. The anomalies are obtained by subtracting the mean climatologies, then smoothing with a 15-day running mean filter. 
shoaling in the eastern basin is associated with the propagation of upwelling equatorial Kelvin waves generated by easterly wind anomalies during pIOD event evolution. The same pattern of anomalous wind stress also forced westward propagation of down welling Rossby waves that deepened the thermocline in the western basin.

Figure 5 shows longitude-time diagrams of the anomalous zonal wind stress and zonal currents along the equator. From early 2007 until March, easterly wind anomalies appeared along the equator, while westerly wind anomalies were observed in the far eastern equatorial Indian Ocean (Fig. 5a). These easterly wind anomalies forced westward zonal current anomalies associated with the upwelling equatorial Kelvin waves along the equator (Fig. 5b). In April strong westerly wind anomalies occurred along the equator that forced eastward zonal current anomalies, which are associated with the down welling equatorial Kelvin waves. Note that the eastward zonal current anomalies reveal westward phase propagation during April - May indicating the important role of Rossby waves in generating this westward phase propagation (Nagura and McPhaden 2010b). Previous studies have shown that the eastern-boundary reflected upwelling Rossby waves from the incoming upwelling Kelvin waves play an important role in zonal current variations along the equatorial Indian Ocean (Nagura and McPhaden 2010b: Iskandar et al. 2013).

In late-April the easterly wind anomalies gradually strengthened and reached its peak in May (Fig. 5a). However, the zonal currents still indicated eastward current anomalies before they turned into weak westward anomalies in lateMay (Fig. 5b). This may suggest that the eastern-boundary reflected Rossby waves play a role in generating eastward zonal current anomalies along the equator during this period. The zonal wind anomalies in the eastern-half of the basin remained easterlies until October 2007, while episodic westerly wind anomalies were observed in the western-half of the ba$\sin$ (Fig. 5a). As oceanic response to the easterly wind anomalies, upwelling equatorial Kelvin waves were generated and the zonal currents along the equator were westward anomalies until late-September (Fig. 5b). The 2007 pIOD event was terminated in October coinciding with the occurrence of westerly wind anomalies along the equator in October associated with a reversal of the monsoon. These westerly wind anomalies forced down welling equatorial Kelvin waves and eastward zonal current anomalies along the equator. Rao et al. (2009) suggested that these westerly wind anomalies associated with the Madden-Julian Oscillation generated down welling Kelvin waves and terminated the 2007 pIOD event. However, it is interesting to note that the initiation of eastward zonal current anomalies during the 2007 pIOD event termination preceded the westerly wind anomalies. Thus, this phase lag may further suggest the importance of the easternboundary reflected Rossby waves in generating eastward zonal current anomalies along the equator.
In order to quantitatively examine the role of windforced and reflected equatorial waves in 2007 pIOD event evolution we evaluated our linear wave model results. The model provides an opportunity to diagnose the wave processes involved in 2007 pIOD event evolution as its output can easily be separated into wind-forced and boundary-reflected waves. Here, we separately evaluate the relative importance of wind-forced and boundary-reflected waves in generating zonal current anomalies during 2007 pIOD event evolution.

Figure 6 shows the evolution of zonal current anomalies induced by the wind-forced and boundary-generated waves during 2007. As shown in the observed zonal current anomalies (Fig. 5b), there were alternate eastward and westward zonal current anomalies in early 2007 though the model over (under) estimates the eastward (westward) currents (Fig. 6a). The eastward current anomalies in the eastern basin during January are associated mainly with the eastern-boundary-reflected Rossby waves (Fig. 6d) with a relatively small contribution coming from the western-boundary-reflected Kelvin waves (Fig. 6b). In the western basin the westward current anomalies were generated mostly by the wind-forced Rossby waves (Fig. 6e), while the western-boundary-reflected Kelvin waves tended to weaken the signals (Fig. 6b).

Strong eastward zonal current anomalies along the equator in April were well captured by the model (Fig. 6a). Apparently, these eastward zonal current anomalies were due mainly to the eastern-boundary-reflected Rossby waves (Figs. 6a, d). The zonal currents turned to the westward anomalies in May as the easterly wind anomalies prevailing (a)

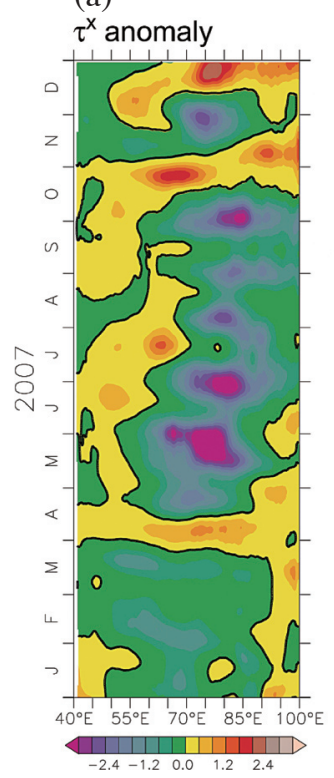

(b)

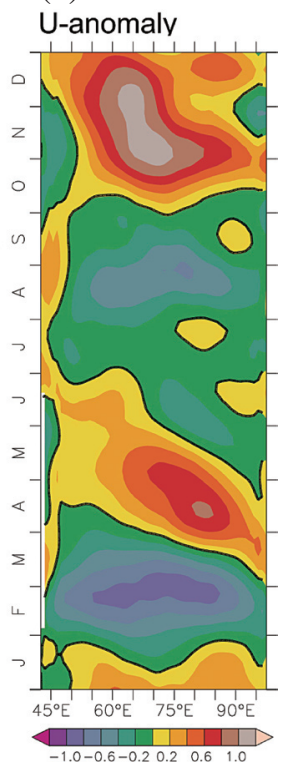

Fig. 5. Time-longitude diagrams of (a) zonal wind stress anomaly $\left(\times 10^{-2} \mathrm{~N} \mathrm{~m}^{-2}\right)$, and (b) zonal current anomaly $\left(\mathrm{m} \mathrm{s}^{-1}\right)$ along the equator. The zero contour is highlighted by thick-black contour. The anomalies are obtained by subtracting the mean climatologies, then smoothing with a 15-day running mean filter. 
(a)

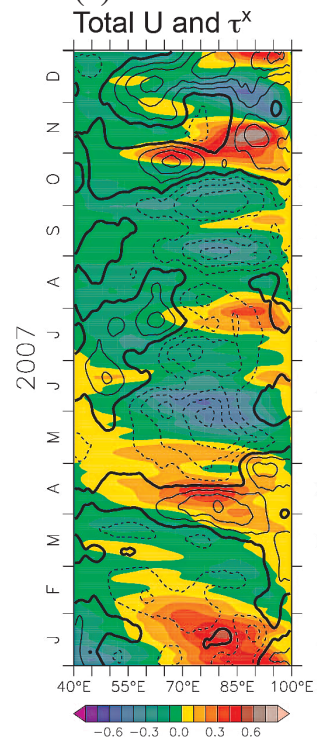

(b)

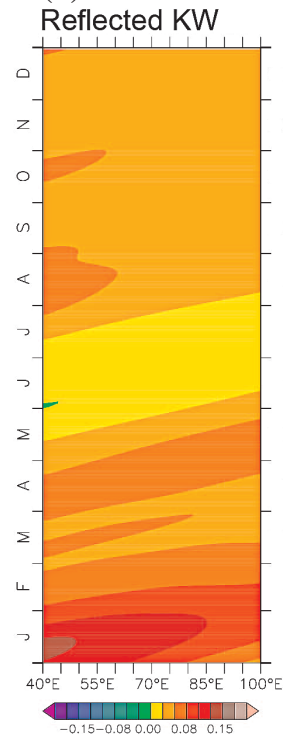

(c)

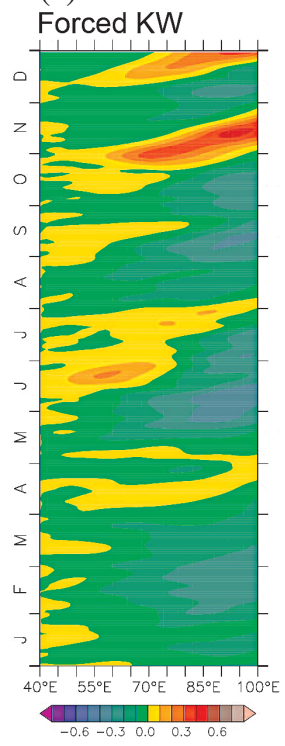

(d)

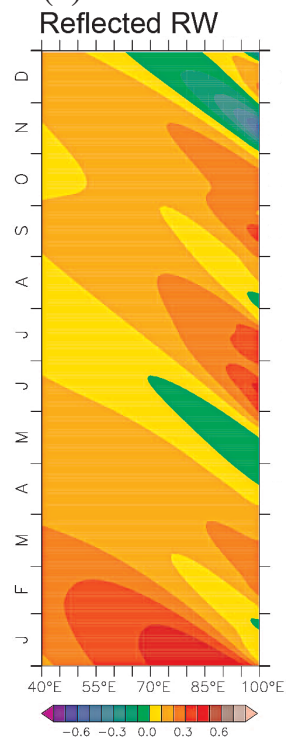

(e)

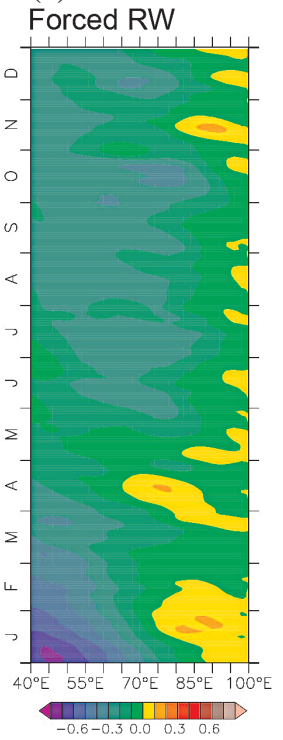

Fig. 6. Time-longitude diagrams of model zonal current anomalies at $15 \mathrm{~m}$ depth along the equator for January - December $2007 \mathrm{for}$ the (a) total solution, (b) reflected Kelvin waves, (c) wind-forced Kelvin waves, (d) reflected Rossby waves, and (e) wind-forced Rossby waves. The contours in Fig. 6a show zonal wind stress anomalies along the equator. The solid (dotted) lines are for westerly (easterly) anomalies. Contour interval is $1.5 \times 10^{-2} \mathrm{~N} \mathrm{~m}^{-2}$ with zero contour highlighted. Note the scale changes in (b).

over the equatorial Indian Ocean. They remained westward anomalies until October in agreement with the observation, with a short reversal to the eastward anomalies in late-July/ early-August. Both the wind-forced Kelvin waves and the eastern-boundary-reflected Rossby waves contribute to generating the eastward zonal current anomalies during late-July/early-August (Figs. 6c - d).

During the development and peak phases of the 2007 pIOD event in August - September, the wind-forced Kelvin waves play a dominant role in generating the westward current anomalies (Figs. 6a, c). These wind-forced Kelvin waves were generated by the easterly wind anomalies, with its maximum located around $80^{\circ}-95^{\circ} \mathrm{E}$ (Fig. 6a). Note that the eastern-boundary-reflected Rossby waves weakened the westward currents during this period (Fig. 6d). The eastward zonal current anomalies that occurred during 2007 pIOD event termination were associated mostly with the wind-forced Kelvin waves (Fig. 6c), although the easternboundary-reflected Rossby waves also contributed (Fig. 6d). These eastward current anomalies were generated by the prevailing westerly wind anomalies along the equatorial Indian Ocean during October in concert with the seasonal monsoon reversal (Fig. 6a).

In order to explicitly assess the causes of the westward and eastward zonal current anomalies observed in the eastern equatorial Indian Ocean during 2007 pIOD event evolution, we plot each wind-forced and boundary-generated equatorial wave component at the buoy location $\left(0^{\circ}, 90^{\circ} \mathrm{E}\right)$ (Fig. 7). Apparently, the westward zonal current anomalies that appeared in May were strongly influenced by the wind-forced
Kelvin waves. By the end of May when the westward current anomalies reached a maximum, the Rossby waves were reflected from the eastern-boundary that tended to weaken the westward current anomalies. The eastward zonal current anomalies that occurred in July were shown generated mostly by these eastern-boundary-reflected Rossby waves. During the peaks phase of the 2007 pIOD event, the westward zonal current anomalies were due mainly to the wind-forced Kelvin waves, where the eastern-boundary-reflected Rossby waves act to reduce the signals from the wind-forced Kelvin wave. It is interesting to note that a phase lag occurred between the total current anomalies and the current anomalies induced by the wind-forced Kelvin waves in the eastern equatorial Indian Ocean during 2007 pIOD event termination in October. The initiation of eastward current anomalies leads the wind-forced Kelvin wave signals. This may suggest the important role of the eastern-boundary-reflected Rossby waves in 2007 pIOD event termination. Note that the contributions from wind-forced Rossby and reflected Kelvin waves were negligible (not shown).

\section{CONCLUSION}

This study examined the role of equatorial waves during the 2007 pIOD event evolution using available observational data and output from a continuously stratified long wave model. The present observational results indicate that the 2007 pIOD event co-occurred with a La Niña event that took place in the Pacific Ocean (Figs. 1a-b). Behera et al. (2008) suggested that during 2007 unusual three Walker 
cells with two ascending branches occurred over the warm SST anomalies in the western Indian Ocean and in the western Pacific. This condition leads to the presence of easterly anomalies over the equatorial Indian Ocean during the boreal spring that triggered the 2007 pIOD event. The 2007 pIOD event was a weak and short-lived pIOD event. It developed in the mid-summer (July), matured in the early-fall (September) and terminated in the mid-fall (October) (Fig. 2).

The corresponding subsurface evolutions of the 2007 pIOD event were also observed in the subsurface zonal currents and subsurface temperature in the central and eastern equatorial Indian Ocean (Figs. 3 - 4). There were strong westward current anomalies observed in the equatorial Indian Ocean before 2007 IOD event initiation in May and June (Fig. 3). During the peak event phase in September, the observed currents were westward anomalies. The event termination was associated with the occurrence of eastward current anomalies concurring with the seasonal monsoon reversal in October. The negative temperature anomalies in the thermocline characterized the subsurface temperature of the 2007 pIOD event (Fig. 4). Interestingly, we observed strong negative temperature anomalies in early 2007 at all mooring locations. We note that these negative temperature signals may have resulted from the previous pIOD event in 2006 (Horii et al. 2008) The negative subsurface temperature anomalies in the central equatorial Indian Ocean lasted until early-October with a short-break in July (Fig. 4a). The negative subsurface temperature anomalies in the central equatorial Indian Ocean gradually changed into positive anomalies in mid-October. The negative subsurface temperature anomalies in the eastern equatorial Indian Ocean observed from early 2007 lasted only until March (Fig. 4b). The subsurface temperature changed into positive anomalies in April. The initiation of negative subsurface temperature anomalies for the 2007 IOD event was first observed in May, two months earlier than the surface IOD signal (Figs. 1a, 4b). Although there was a weakening of the negative subsurface temperature anomalies in July, these anomalies persisted for about 6 months until mid-October, before they were suddenly replaced by positive anomalies in early-November. This termi- nation of the subsurface signals coincided with the seasonal reversal of the monsoonal winds in October/November.

The 2007 pIOD event evolution is linked to the equatorial wave dynamics. We observed several episodic easterly wind anomalies during 2007 pIOD initiation, which generated upwelling equatorial Kelvin waves and westward current anomalies (Figs. 5a, b). The westward current anomalies along the equator generated by strong easterly wind anomalies in May and July were weakened by the easternboundary-reflected Rossby waves generated by the previous incoming upwelling Kelvin waves in March/April. As the IOD came to its peak in August - September, strong westward current anomalies were observed along the equator. During the 2007 pIOD event termination in October, easterly wind anomalies along the equator were replaced by westerly wind anomalies. At the same time we observed strong eastward current anomalies along the equator suggesting the important role of equatorial waves in the event termination.

We then evaluated the relative roles of wind-forced and boundary-generated waves in the 2007 pIOD event evolution using a simple linear wave model. The model well simulated the zonal current patterns associated with the IOD event. One of the main advantages of using a linear wave model is that it allows us to separate directly the windforced waves from the boundary-generated waves (Fig. 6). The model shows that during the development and mature phases of the 2007 pIOD event, the wind-forced Kelvin waves play an important role in generating the westward zonal current anomalies along the equator (Figs. 6a, c, 7). The eastern-boundary-reflected Rossby waves tended to weaken the wind-forced Kelvin wave signals (Figs. 6d, 7).

The 2007 pIOD event termination in October co-occurred with the presence of eastward zonal current anomalies along the equator (Fig. 6b). Previous studies have shown that the intra-seasonal Kelvin waves forced by the intra-seasonal winds associated with the MJO terminated the 2007 pIOD event (Rao et al. 2009). In this study we found that both the wind-forced Kelvin and the eastern-boundary-reflected Rossby waves have comparable contributions to generating these eastward zonal currents (Figs. 6a, c, d, 7). However, it

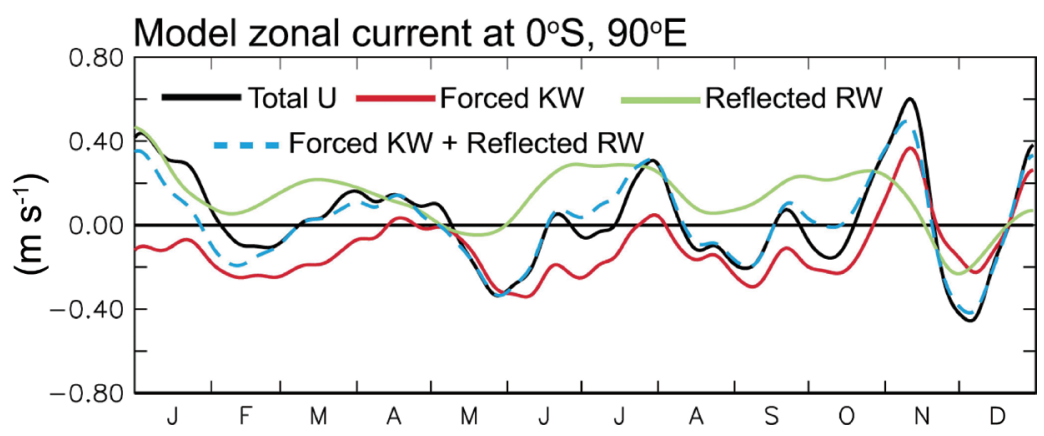

Fig. 7. Time series of zonal current anomaly at $15 \mathrm{~m}$ depth at $0^{\circ}, 90^{\circ} \mathrm{E}$ for January - December 2007 from reflected Rossby wave (green), forced Kelvin wave (red), total solution (black), and the sum of reflected Rossby and forced Kelvin waves (blue-dashed). 
should be noted that a phase lag occurred between the eastward zonal current anomalies and the anomalies generated by the wind-forced Kelvin waves (Fig. 7). The initiation of eastward current anomalies leads the wind-forced Kelvin wave signals. This highlights the importance of the eastern-boundary-reflected Rossby waves in generating the eastward zonal current anomalies during 2007 pIOD event termination.

Compared to the 2006 pIOD event, the 2007 pIOD event was much weaker and shorter. We noted that during the 2006 pIOD event strong easterly wind anomalies were observed during event development in late-July and continuously eastward until December 2006 (Horii et al. 2008; Iskandar 2012). This easterly anomaly forced strong upwelling Kelvin waves, leading to strong negative SST anomalies in the eastern equatorial Indian Ocean off Sumatra and Java. Meanwhile, during the 2007 pIOD event, easterly wind anomalies were first observed in May and remained eastward until November. However, the amplitude of these easterly anomalies was much weaker than those observed during the 2006 pIOD event evolution. During the 2007 pIOD event evolution we observed frequent westerly wind anomalies that forced intra-seasonal down welling Kelvin waves along the equator. These down welling Kelvin waves tended to weaken anomalous upwelling in the eastern equatorial Indian Ocean.

Acknowledgement This work is supported by the University of Sriwijaya through Grant-in-Aid for Researcher. The first author is supported by the Indonesia Toray Science Foundation (ITSF). This is PSGPI contribution number 14001.

\section{REFERENCES}

Behera, S. K., J. J. Luo, and T. Yamagata, 2008: Unusual IOD event of 2007. Geophys. Res. Lett., 35, L14S11, doi: 10.1029/2008GL034122. [Link]

Bonjean, F. and G. S. E. Lagerloef, 2002: Diagnostic model and analysis of the surface currents in the tropical Pacific ocean. J. Phys. Oceanogr., 32, 2938-2954, doi: 10.1 175/1520-0485(2002)032<2938:DMAAOT>2.0.CO;2. [Link]

Cai, W., A. Pan, D. Roemmich, T. Cowan, and X. Guo, 2009: Argo profiles a rare occurrence of three consecutive positive Indian Ocean Dipole events, 2006-2008. Geophys. Res. Lett., 36, L08701, doi: 10.1029/2008GL037038. [Link]

Chambers, D. P., B. D. Tapley, and R. H., Stewart, 1999: Anomalous warming in the Indian Ocean coincident with El Niño. J. Geophys. Res., 104, 3035-3047, doi: 10.1029/1998JC900085. [Link]

Clarke, A. J. and X. Liu, 1993: Observations and dynamics of semiannual and annual sea levels near the eastern equatorial Indian Ocean boundary. J. Phys. Oceanogr., 23, 386-399, doi: 10.1175/1520-0485(1993)023<0386: OADOSA > 2.0.CO;2. [Link]
Feng, M. and G. Meyers, 2003: Interannual variability in the tropical Indian Ocean: A two-year time-scale of Indian Ocean Dipole. Deep-Sea Res. Part II-Top. Stud. Oceanogr., 50, 2263-2284, doi: 10.1016/S0967-0645(03)00056-0. [Link]

Han, W., 2005: Origins and dynamics of the 90-day and 30-60-day variations in the equatorial Indian Ocean. $J$. Phys.Oceanogr.,35,708-728, doi: 10.1175/JPO2725.1. [Link]

Horii, T., H. Hase, I. Ueki, and Y. Masumoto, 2008: Oceanic precondition and evolution of the 2006 Indian Ocean dipole. Geophys. Res. Lett., 35, L03607, doi: 10.1029/2007GL032464. [Link]

Iskandar, I., 2012: The role of equatorial oceanic waves in the activation of the 2006 Indian Ocean Dipole. ITB J. Sci., 44, 113-128, doi: 10.5614/itbj.sci.2012.44.2.2. [Link]

Iskandar, I., M. Irfan, and F. Syamsuddin, 2013: Why was the 2008 Indian Ocean Dipole a short-lived event? Ocean Sci. J., 48, 149-160, doi: 10.1007/s12601-013-0012-3. [Link]

Le Blanc, J. L. and J. P. Boulanger, 2001: Propagation and reflection of long equatorial waves in the Indian Ocean from TOPEX/POSEIDON data during the 1993-1998 period. Climate Dyn., 17, 547-557, doi: 10.1007/ s003820000128. [Link]

McPhaden, M. J., G. Meyers, K. Ando, Y. Masumoto, V. S. N. Murty, M. Ravichandran, F. Syamsudin, J. Vialard, L. Yu, and W. Yu, 2009: RAMA: The Research Moored Array for African-Asian-Australian monsoon analysis and prediction. Bull.Amer.Meteorol.Soc.,90, 459-480, doi: 10.1175/2008BAMS2608.1. [Link]

McPhaden, M. J. and M. Nagura, 2014: Indian Ocean dipole interpreted in terms of recharge oscillator theory. $\mathrm{Cli}$ mate Dyn., 42, 1569-1586, doi: 10.1007/s00382-0131765-1. [Link]

Meyers, G., P. McIntosh, L. Pigot, and M. Pook, 2007: The years of El Niño, La Niña, and interactions with the tropical Indian Ocean. J. Climate, 20, 2872-2880, doi: 10.1175/JCLI4152.1. [Link]

Murtugudde, R., J. P. McCreary, and A. J. Busalacchi, 2000: Oceanic processes associated with anomalous events in the Indian Ocean with relevance to 1997-98. J. Geophys. Res., 105, 3295-3306.

Nagura, M. and M. J. McPhaden, 2010a: Wyrtki Jet dynamics: Seasonal variability. J. Geophys. Res., 115, C07009, doi: 10.1029/2009JC005922. [Link]

Nagura, M. and M. J. McPhaden, 2010b: Dynamics of zonal current variations associated with the Indian Ocean Dipole. J. Geophys. Res., 115, C11026, doi: 10.1029/2010JC006423. [Link]

Rao, S. A., S. K. Behera, Y. Masumoto, and T. Yamagata, 2002: Interannual subsurface variability in the Tropical Indian Ocean with a special emphasis on the Indian 
Ocean dipole. Deep-Sea Res. Part II-Top. Stud. Oceanogr., 49, 1549-1572, doi: 10.1016/S0967-0645 (01)00158-8. [Link]

Rao, S. A. and T. Yamagata, 2004: Abrupt termination of Indian Ocean dipole events in response to intraseasonal disturbances. Geophys. Res. Lett., 31, L19306, doi: 10.1029/2004GL020842. [Link]

Rao, S. A., J. J. Luo, S. K. Behera, and T. Yamagata, 2009: Generation and termination of Indian Ocean dipole events in 2003, 2006 and 2007. Climate Dyn., 33, 751767, doi: 10.1007/s00382-008-0498-z. [Link]

Roemmich, D. and J. Gilson, 2009: The 2004-2008 mean and annual cycle of temperature, salinity, and steric height in the global ocean from the Argo Program. Prog. Oceanogr., 82, 81-100, doi: 10.1016/j. pocean.2009.03.004. [Link]
Saji, N. H., B. N. Goswami, P. N. Vinayachandran, and T. Yamagata, 1999: A dipole mode in the tropical Indian Ocean. Nature, 401, 360-363, doi: 10.1038/43854. [Link]

Vinayachandran, P. N., N. H. Saji, and T. Yamagata, 1999: Response of the Equatorial Indian Ocean to an unusual wind event during 1994. Geophys. Res. Lett., 26, 1613 1616, doi: 10.1029/1999GL900179. [Link]

Webster, P. J., A. M. Moore, J. P. Loschnigg, and R. R. Leben, 1999: Coupled ocean-atmosphere dynamics in the Indian Ocean during 1997-98. Nature, 401, 356-360, doi: 10.1038/43848. [Link]

Yuan, D. and H. Liu, 2009: Long-wave dynamics of sea level variations during Indian Ocean Dipole events. J. Phys. Oceanogr., 39, 1115-1132, doi: 10.1175/ 2008JPO3900.1. [Link] 